\title{
The expanding scope of pharmacists' practice: implications for physicians
}

\author{
Cara Tannenbaum MD MSc, Ross T. Tsuyuki PharmD MSc
}

Competing interests: Cara Tannenbaum has received payments from Pfizer for board membership and from Allergan for consultancy. Ross Tsuyuki has received payments from Bristol-

Myers Squibb,

AstraZeneca, PharmaSmart International, Merck and Abbott for consultancy, and from Boehringer Ingelheim for board membership. Ross Tsuyuki's institution has received grants or has grants pending from Sanofi and AstraZeneca.

This article has been peer reviewed.

Correspondence to: Cara Tannenbaum, cara.tannenbaum @umontreal.ca

CMAJ 2013. DOI:10.1503 /cmaj.121990
$\mathrm{R}$ ecent legislative and regulatory changes have supported a broadening of the scope of pharmacists' practice across Canada. Under the authority of these new regulations, hospital- and community-based pharmacists are able to renew, refuse to fill, adjust or substitute prescriptions. Pharmacists may also initiate drug therapy for certain self-limiting conditions, order and interpret laboratory tests, and administer injections and vaccines. Each province and territory has its own body for registering and regulating pharmacy practice, thus the scope of changes varies accordingly. Table $1^{1}$ summarizes the activities that havebeen approved or are pending legislation in each province and territory as of January 2013.

A growing recognition that patients' health care demands are exceeding physicians' capacity to address them has contributed in part to the evolution of pharmacists' practice. Increasingly, physicians are managing a higher prevalence of chronic disease and multimorbidity in their patients. ${ }^{2.3}$ In 2003, the Canadian Medical Association issued a joint statement endorsed by the Canadian Pharmacists Association and the Canadian Nurses Association on the determination of shared scopes of practice for allied health professionals. ${ }^{4}$ The statement reinforced that policy decisions taken to expand the scope of practice for health professionals must put patients first and reflect physicians' commitment to professional-

ism, lifelong learning and patient safety. Subsequent regulatory changes across Canada have defined the areas where these changes can occur.

Internationally, pharmacists are increasingly involved in providing joint patient care. The United Kingdom, New Zealand and the United States have all moved toward various forms of independent or collaborative prescribing..$^{5-7}$ Countries in which pharmacists can be trained and certified to administer vaccines include the US, the UK, Ireland and Portugal..$^{7-10}$ Whereas patients will likely benefit from increased pharmacist care, a number of concerns may arise. How will pharmacists communicate with physicians when medication adjustments occur? What are the liability issues for physicians when such changes occur? Will there be a loss in quality of care or physician income with these changes?

This analysis reviews the opportunities and evidence for an expansion in the scope of pharmacists' practice. The ethical, liability and financial implications for physicians will be addressed. Future considerations include integration of interprofessional education for physicians as well as for medicine and pharmacy students at the graduate and postgraduate levels to improve the working relationship between physicians and pharmacists in real-world settings.

\section{Evidence review}

There is robust evidence from randomized trials that pharmacist involvement in patient care can provide benefit. Favourable disease-specific outcomes have been documented for the management of hypertension, dyslipidemia, heart failure, anticoagulation therapy, asthma and diabetes. A systematic review of 19 randomized trials of pharmacist care for hypertension showed a reduction in systolic blood pressure of 8.1/3.8 (95\% confidence interval [CI] 5.9-10.2/ 2.3-5.3) $\mathrm{mm} \mathrm{Hg}$ compared with usual care. ${ }^{10}$ Pharmacist care for dyslipidemia reduced lowdensity lipoprotein cholesterol by 0.28 (95\% CI $0.12-0.44) \mathrm{mmol} / \mathrm{L}$ and helped achieve target 
lipid values. ${ }^{11}$ A systematic review of pharmacist care in patients with heart failure showed a reduction in hospital admission for heart failure of $31 \%$ (95\% CI 6\%-49\%), compared with usual physician and nurse care. ${ }^{12}$ Collaborative care by nonspecialist pharmacists working with family doctors to manage the treatment of patients with heart failure also improved prescribing of disease-modifying medications, but showed no difference in death or hospital admission for worsening heart failure. ${ }^{13}$ Improved control of international normalized ratios and patient satisfaction have been consistently reported in pharmacist-led anticoagulation clinics. ${ }^{14}$ Asthma and diabetes care by pharmacists can result in improvements in pulmonary function tests and glycated hemoglobin. ${ }^{15-18}$ Services provided by pharmacists in community or ambulatory outpatient settings have been shown to improve medication management and adherence. ${ }^{19,20}$ Whether pharmacist care is cost-effective remains to be determined. Trials are currently ongoing in Canada and elsewhere to determine where added value can best be derived to improve patient outcomes. ${ }^{21}$ Evidence already shows that pharmacists' provision of vaccination services increases vaccination rates and is safe and well received by patients. ${ }^{8,9}$

\section{Opportunities for successful physician-pharmacist collaboration}

More than $10 \%$ of emergency department visits in Canada result from drug-related problems, and $80 \%$ of older adults admitted to hospital with polypharmacy have at least 1 detectable cytochrome P450-mediated drug-drug interaction. ${ }^{22,23}$ Several harmful drug-drug interactions can lead to hospital admission in the elderly, with the most frequently implicated drugs being warfarin, insulin, oral antiplatelet agents, angiotensin-converting enzyme inhibitors, antibiotics, benzodiazepines and oral hypoglycemic agents. $^{24,25}$ Collaborative management with pharmacists has the potential to reduce drug-related outpatient and emergency department visits.

Optimal prescribing for patients with multimorbidity is another area where physicians stand to benefit from pharmacists' involvement. ${ }^{26-28}$ People with 1-2 chronic conditions take 3-4 prescription medications on average, and seniors

Table 1: Summary of pharmacists' expanded scope of practice activities across Canada, as of January 2013'

\begin{tabular}{|c|c|c|c|c|c|c|c|c|c|c|c|c|c|}
\hline \multirow[b]{2}{*}{ Activity } & \multicolumn{13}{|c|}{ Province/territory } \\
\hline & $\mathrm{BC}$ & Alta. & Sask. & Man. & Ont. & Que. & NB & NS & PEI & $\mathrm{NL}$ & NWT & YT & Nunavut \\
\hline $\begin{array}{l}\text { Provide emergency } \\
\text { prescription refills }\end{array}$ & I & I & I & $P$ & I & $I^{*}$ & I & I & I & I & I & $X$ & $\mathrm{X}$ \\
\hline $\begin{array}{l}\text { Renew/extend } \\
\text { prescriptions }\end{array}$ & I & I & I & It & I & $I^{*} \mp$ & I & I & I & I & I & $X$ & $X$ \\
\hline $\begin{array}{l}\text { Change drug dosages or } \\
\text { formulations }\end{array}$ & I & I & I & $\mathrm{P}$ & I & I‡§ & I & I & $\mathrm{X}$ & I & $\mathrm{X}$ & $\mathrm{X}$ & $\mathrm{X}$ \\
\hline $\begin{array}{l}\text { Make therapeutic } \\
\text { substitutions }\end{array}$ & I & I & I & $X$ & $X$ & I‡§ & I & I & $\mathrm{X}$ & $X$ & $X$ & $X$ & $X$ \\
\hline $\begin{array}{l}\text { Prescribe for minor } \\
\text { ailments }\end{array}$ & $X$ & $x$ & I & $x$ & $X$ & $P$ & $P$ & I & $X$ & $x$ & $X$ & $X$ & $X$ \\
\hline $\begin{array}{l}\text { Initiate prescription drug } \\
\text { therapy }\end{array}$ & $X$ & I & ।| & $P$ & $I^{* *}$ & I§ & It† & 19 & $x$ & $x$ & $X$ & $X$ & $X$ \\
\hline $\begin{array}{l}\text { Order and interpret } \\
\text { labratory tests }\end{array}$ & $X$ & 1 & $x$ & $P$ & $P$ & 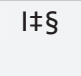 & 1 & $P$ & $x$ & $X$ & $X$ & $X$ & $x$ \\
\hline $\begin{array}{l}\text { Administer drugs by } \\
\text { injection }\end{array}$ & I & I & $x$ & $P$ & はキ & $P$ & I & $P$ & $x$ & $X$ & $X$ & $X$ & $x$ \\
\hline \multicolumn{14}{|c|}{ 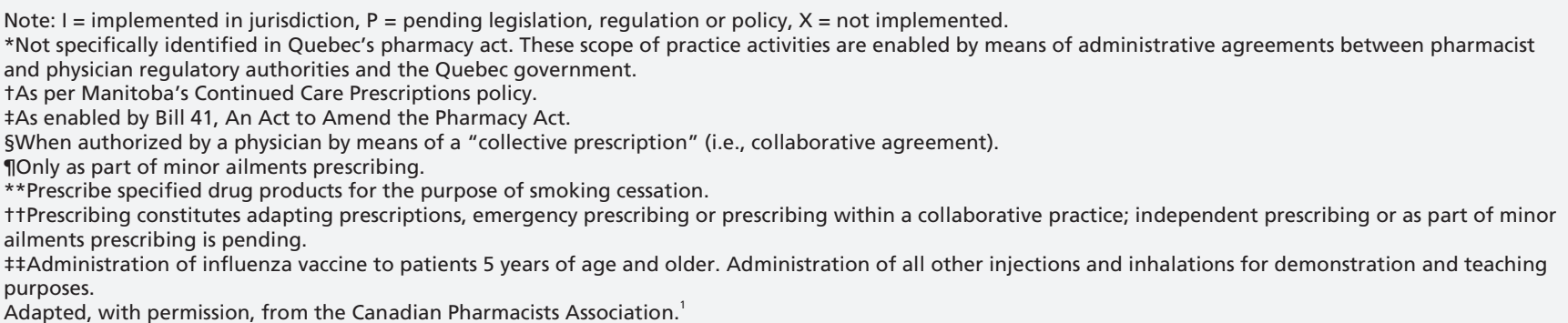 } \\
\hline
\end{tabular}


with 3 or more chronic conditions take $6 .{ }^{29,30}$ The number of prescription medications is independently associated with an increased rate of emergency department use in Canada. ${ }^{2}$ Effective and safe prescribing in the context of polypharmacy (the use of $\geq 5$ drugs) requires intricate knowledge of doses and dosing regimens, pharmacology, pharmacokinetics and pharmacodynamics, drug-drug interactions and drug monitoring. ${ }^{30}$ Arguably, pharmacists acquire a much greater level of expertise in these areas in the course of their training than physicians, and collaborative care would be synergistic.

Reducing inappropriate prescriptions - medication with excessive risk for which safer alternatives are available - is a challenging problem in Canada. ${ }^{31,32}$ Drugs such as glyburide and the short-acting benzodiazepines have appeared on the 2012 Beers list of drugs to avoid in older adults, and recent warnings have been issued by Health Canada about denosumab and simvastatin, for example. ${ }^{33,34}$ Pharmacists can help physicians keep abreast of changes in guidance to minimize drug-related risk and substitute inappropriate prescriptions. ${ }^{35}$

Deprescribing for patients with multimorbidity may constitute an essential step in minimizing drug-related iatrogenesis. ${ }^{36,37}$ Some physicians admit discomfort in ceasing or reducing medications in patients with complex drug regimens. ${ }^{38}$ Pharmacists can offer support to deprescribe, by helping with tapering protocols for discontinuing central nervous system and cardiovascular drugs that are known to be associated with the highest frequency of adverse events related to drug withdrawal. ${ }^{39}$

\section{Ethical, legal, financial and professional considerations}

Physicians have a clear responsibility set out in the guiding principles established by the professional code of ethics of the Canadian Medical Association to maintain professionalism and collegiality with pharmacists in all aspects of patient care, including open and respectful discussion about patients' medication management. ${ }^{40}$ Legally, physicians are held accountable to the specific codes of conduct and standards of practice of the college of physicians and surgeons in each provincial jurisdiction. Although small differences exist, each provincial code of conduct encourages physicians to collaborate with pharmacists to best manage the treatment of their patients within a reasonable range of their skills and knowledge.

Overlapping scopes of practice with pharma- cists may attenuate, or paradoxically escalate, the potential for patient injuries to occur owing to prescribing changes or miscommunication about medication monitoring. ${ }^{41,42}$ The Canadian Medical Protective Association found that medications were the principal area of concern in $17 \%$ of its 1249 medicolegal cases filed against physicians involving patients aged 65 years and older from Jan. 1, 2005, to Dec. 31, 2010. ${ }^{43}$ As pharmacists more actively participate in medication management, physicians should be aware that in interprofessional models of care, every member of the team is accountable for the care he or she provides and is not to be held directly liable for the acts of others. ${ }^{42,44}$ In a case where a physician is not consulted or provided with a notice of change to a prescribed treatment, the physician would generally not be held liable for wrongdoing on the part of the pharmacist and could not be sued for any injuries the patient may suffer due to the modification. However, a physician may be exposed to liability if he or she becomes aware of an erroneous prescribing decision made by the pharmacist but fails to take action to prevent harm to the patient. Similarly, if a patient commences a civil action or files a complaint with the college because of injuries sustained as a result of a pharmacist's prescribing decision, a physician involved in treating that patient may be named as a codefendant in that action and be held jointly liable.

As with physicians, pharmacists must exercise all prescribing and other activities within the practice framework developed by the regulatory bodies in each province and must hold liability insurance. For instance, pharmacists in Alberta and Quebec are required to have a minimum of $\$ 2$ million dollars in personal liability coverage. All pharmacists are required to participate in ongoing professional development and to participate in their college's competency program. The Blueprint for Pharmacy initiative developed by the Canadian Pharmacists Association aims to augment training opportunities for practising pharmacists and to increase the rate of enrolment of pharmacy students into residency programs. The National Association of Pharmacy Regulatory Authorities is currently seeking to standardize training programs and oversight for pharmacists' activities across the country. Programs that teach pharmacists how to administer injections, and accreditation procedures for vaccination delivery in concert with public health requirements for appropriate places to store and administer vaccines are mandatory.

Financial incentives have been put in place to encourage interdisciplinary collaboration. Physician fee schedules for participation in telephone 
consultations initiated by pharmacists for advice about patient care or for monthly anticoagulant supervision and prescription renewal are already in effect (range \$8.00-\$29.54 per consultation) or are being negotiated in many Canadian provinces. Telephone, fax and email are considered appropriate forms of consultation in many provinces except in Ontario and Prince Edward Island, where the only acceptable medium is the telephone. Physicians should consult the list of insured services in their province for their specialty, because reimbursement fees for prescription renewal are available in only half the provinces and range from $\$ 3.50$ to $\$ 15.95$.

Physicians may be concerned about increased frequency of patient visits. Simpson and colleagues ${ }^{45}$ performed an economic evaluation of data derived from a Canadian randomized controlled trial that tested a pharmacist-led intervention in cholesterol risk management. Their analysis showed no increase in overall patient visits to physicians, despite improved cardiovascular risk management. ${ }^{45}$

\section{Next steps}

In the interests of patient care and the joint responsibilities arising from an expanded scope of pharmacists' practice, physicians should reflect on the best way to improve adequate and timely communication with pharmacists in their practice. Physicians may wish to communicate with pharmacists by telephone, because pharmacists can be easily reached during working hours. However, physicians are rarely able to respond immediately to telephone calls to discuss patient care. Reciprocal communication arrangements should be made that allow physicians to be notified by pharmacists in a timely fashion about prescription renewals, modifications or initiation of new therapy for their patients. The use of computer-based prescribing and electronic health records could facilitate this task; if these are unavailable, faxes or emails could be sent directly to the physician. Communication is a means of not only relaying messages about prescription changes, but also clarifying who will be responsible for ordering tests and acting on the results.

Interprofessional education may be required to establish effective collaboration between physicians and pharmacists. ${ }^{46}$ Many universities are making special efforts to bring together undergraduate and graduate students in the fields of pharmacy and medicine for training in interdisciplinary care. At the Université de Montréal and University of Alberta, students from the nursing, medical and pharmacy faculties are already being jointly exposed to complex patient cases to prepare for interdisciplinary functioning in the real-world setting. Regional continuing medical education courses on the expanded scope of pharmacists' practice could provide working knowledge to physicians on how to optimize collaborative care.

Trusting relationships between physicians and pharmacists may take time to develop, similar to the relationships that develop between family practitioners and specialists. Investing time and effort in such relationships and getting to know pharmacists' competencies and the tasks they wish to share is worthwhile. Asking pharmacists to perform medication reviews for patients with complex illnesses and acknowledging useful suggestions is an excellent place to start. Once established, collaborative care with pharmacists will likely yield tremendous benefits to both patients and physicians. The expanding scope of pharmacists' practice offers many opportunities to improve patient care. However, it is also an ongoing process that must be evaluated as regulated activities change, new pharmacists enter practice and scopes of activities continue to expand.

\section{References}

1. Summary of pharmacists' expanded scope of practice activities across Canada. Ottawa (ON): Canadian Pharmacists Association; 2013. Available: http://blueprintforpharmacy.ca/docs/kt-tools /pharmacists'-expanded-scope_summary-chart---cpha---june-10 -2013.pdf (accessed 2013 July 25).

2. Terner M, Reason B, McKeag AM, et al. Chronic conditions more than age drive health system use in Canadian seniors. Healthc Q 2011;14:19-22.

3. National Physician Survey, 2010. Results for family physicians by certification, sex, and age. Mississauga (ON): National Physician Survey; 2010. Available: http://nationalphysiciansurvey.ca /wp-content/uploads/2012/09/2010-FP-Q23.pdf (accessed 2012 Nov. 2).

4. Joint statement on scopes of practice. Ottawa (ON): Canadian Medical Association; 2003. Available: policybase.cma.ca/dbtw -wpd/PolicyPDF/PD03-07.pdf (accessed 2012 Nov. 2)

5. Latter S, Blenkinsopp A. Non-medical prescribing: current and future contribution of pharmacists and nurses. Int J Pharm Pract 2011;19:381-2

6. Revised pharmacist prescriber scope of practice definition. Wellington (New Zealand): Pharmacy Council of New Zealand; 2011. Available: www.pharmacycouncil.org.nz/cms_show _download.php?id=253 (accessed 2012 Nov. 12).

7. McGlew J. Collaborative drug therapy management by state. Lenexa (KS): American College of Clinical Pharmacy; 2012.

8. Seasonal influenza vaccination programme in pharmacies - evidence base and framework. Dublin (Ireland): The Pharmaceutical Society of Ireland.; 2011. Available: www.thepsi.ie/Libraries /Pharmacy_Practice/Final_Seasonal_Influenza_Vaccination _Programme_in_Pharmacies_Evidence_Base_and_Framework sflb.ashx (accessed 2013 Feb. 26).

9. Francis M, Hinchliffe A. Vaccination services through community pharmacy: a literature review. Cardiff (Wales): Public Health Wales; 2010. Available: www2.nphs.wales.nhs.uk:8080/Health ServiceQDTDocs.nsf/public/CBDDC3C0BE9449398025793 B00341A6F/\$file/Vaccination\%20services\%20through\% 20 community\%20pharmacy\%20v1a.pdf (accessed 2013 Feb. 26).

10. Santschi V, Chiolero A, Burnand B, et al. Impact of pharmacist care in the management of cardiovascular disease risk factors. Arch Intern Med 2011;171:1441-53.

11. Charrois TL, Zolezzi M, Koshman SL, et al. A systematic review of the evidence for pharmacist care of patients with dyslipidemia. Pharmacotherapy 2012;32:222-33. 
12. Koshman SL, Charrois TL, Simpson SH, et al. Pharmacist care of patients with heart failure: a systematic review of randomized trials. Arch Intern Med 2008;168:687-94.

13. Lowrie R, Mair FS, Greenlaw N, et al. Pharmacist intervention in primary care to improve outcomes in patients with left ventricular systolic dysfunction. Eur Heart J 2012;33:314-24.

14. Bungard TJ, Gardner L, Archer SL, et al. Evaluation of a pharmacist-managed anticoagulation clinic: improving patient care. Open Med 2009;3:e16-21.

15. Benavides S, Rodriguez JC, Maniscalco-Feichtl M. Pharmacist involvement in improving asthma outcomes in various healthcare settings: 1997 to present. Ann Pharmacother 2009;43:85-97.

16. Wubben DP, Vivian EM. Effects of pharmacist outpatient interventions on adults with diabetes mellitus: a systematic review. Pharmacotherapy 2008;28:421-36.

17. Evans CD, Watson E, Eurich DT, et al. Diabetes and cardiovascular disease interventions by community pharmacists: a systematic review. Ann Pharmacother 2011;45:615-28.

18. Collins C, Limone BL, Scholle JM, et al. Effect of pharmacist intervention on glycemic control in diabetes. Diabetes Res Clin Pract 2011;92:145-52.

19. Nkansah N, Mostovetsky O, Yu C, et al. Effect of outpatient pharmacists' non-dispensing roles on patient outcomes and prescribing patterns. Cochrane Database Syst Rev 2010;(7):CD000336.

20. Cutrona SL, Choudhry NK, Fischer MA, et al. Modes of delivery for interventions to improve cardiovascular medication adherence. Am J Manag Care 2010;16:929-42.

21. Charrois TL, McAlister FA, Cooney D, et al. Improving hypertension management through pharmacist prescribing: the rural Alberta clinical trial in optimizing hypertension (Rural RxACTION): trial design and methods. Implement Sci 2011;6:94.

22. Zed PJ, Abu-Laban RB, Balen RM, et al. Incidence, severity and preventability of medication-related visits to the emergency department: a prospective study. CMAJ 2008;178:1563-9.

23. Zakrzewski-Jakubiak H, Doan J, Lamoureux P, et al. Detection and prevention of drug-drug interactions in the hospitalized elderly: utility of a new cytochrome P450-based software. Am J Geriatr Pharmacother 2011;9:461-70.

24. Hines LE, Murphy JE. Potentially harmful drug-drug interactions in the elderly: a review. Am J Geriatr Pharmacother 2011;9:364-77.

25. Budnitz DS, Lovegrove MC, Shehab N, et al. Emergency hospitalizations for adverse drug events in older Americans. $N$ Engl J Med 2011;365:2002-12

26. Smith SM, O'Kelly S, O'Dowd T. GPs' and pharmacists' experiences of managing multimorbidity: a 'Pandora's box.' $\mathrm{Br} J$ Gen Pract 2010;60:285-94

27. Tarn DM, Paterniti DA, Wenger NS, et al. Older patient, physician and pharmacist perspectives about community pharmacists roles. Int J Pharm Pract 2012;20:285-93.

28. Hatah E, Braund R, Duffull S, et al. General practitioners' perceptions of pharmacists' new services in New Zealand. Int J Clin Pharm 2012;34:364-73.

29. Reason B, Terner M, Moses McKeag A, et al. The impact of polypharmacy on the health of Canadian seniors. Fam Pract 2012; 29:427-32.

30. Gallagher P, Barry P, O'Mahony D. Inappropriate prescribing in the elderly. J Clin Pharm Ther 2007;32:113-21.

31. Canadian Institute for Health Information. Drug claims by seniors: an analysis focusing on potentially inappropriate medication use, 2000 to 2006. Ottawa (ON): The Institute; 2007. Available: https://secure.cihi.ca/free_products/Potentially_Inappropriate _Medications_EN.pdf (accessed 2012 Aug. 25).

32. Conseil du Médicament. Étude sur la prévalence d l'usage d'ordonnances potentiellement non appropriées (OPNA) chez les aînés du Québec, de 2000 à 2006. Québec (QC): Gouvernement du Québec; 2009. ISBN 978-2-550-55845-3.

33. The American Geriatrics Society 2012 Beers Criteria Update Expert Panel. American Geriatrics Society updated Beers criteria for potentially inappropriate medication use in older adults. J Am Geriatr Soc 2012;60:616-31.

34. Drugs and health products: advisories, warnings and recalls for health professionals. Ottawa (ON): Health Canada; updated 2013. Available: www.hc-sc.gc.ca/dhp-mps/medeff/advisories-avis /prof/index-eng.php (accessed 2012 Nov. 18).

35. Castelino RL, Bajorek BV, Chen TF. Targeting suboptimal prescribing in the elderly: a review of the impact of pharmacy services. Ann Pharmacother 2009;43:1096-106.

36. Gnjidic D, Le Couteur DG, Kouladjian L, et al. Deprescribing trials: methods to reduce polypharmacy and the impact on prescribing and clinical outcomes. Clin Geriatr Med 2012;28:237-53.

37. Scott IA, Gray LC, Martin JH, et al. Minimizing inappropriate medications in older populations: a 10-step conceptual framework. Am J Med 2012;125:529-37.

38. Schuling J, Gebben H, Veehof LJG, et al. Deprescribing medication in very elderly patients with multimorbidity: the view of Dutch GPs. A qualitative study. BMC Fam Pract 2012;13:56.

39. Graves T, Hanlon JT, Schmader KE, et al. Adverse events after discontinuing medications in elderly outpatients. Arch Intern Med 1997;157:2205-10.

40. CMA code of ethics. Ottawa (ON): The Canadian Medical Association; updated 2004. Available: policybase.cma.ca/dbtw -wpd/PolicyPDF/PD04-06.pdf (accessed 2012 Nov. 18)

41. The new reality: expanding scopes of practice. Ottawa $(\mathrm{ON})$ The Canadian Medical Protective Association; 2010. Available: www.cmpa-acpm.ca/cmpapd04/docs/member_assistance/more /com_p1001_3-e.cfm (accessed 2012 Oct. 1).

42. Collaborative care and medication monitoring: Who's responsi ble? Ottawa (ON): The Canadian Medical Protective Association; 2008. Available: www.cmpa-acpm.ca/cmpapd04/docs /resource_files/infoletters/2003/com_il0320_1-e.cfm (accessed 2012 Oct. 1).

43. Cranney A. Risk management in elderly patients: medication issues. CMPA Perspective 2011;3:3-5. Available: www.cmpa-acpm .ca/cmpapd04/docs/resource_files/perspective/2011/02/com _p1102_1-e.cfm (accessed 2012 Oct. 1)

44. Liability issues when collaborating with prescribing pharmacists. Ottawa (ON): The Canadian Medical Protective Association; 2009. Available: www.cmpa-acpm.ca/cmpapd04/docs/member_assistance /more/com_p0904_5-e.cfm (accessed 2012 Oct. 1).

45. Simpson SH, Johnson JA, Tsuyuki RT. Economic impact of community pharmacist intervention in cholesterol risk management an evaluation of the study of cardiovascular risk intervention by pharmacists (SCRIP). Pharmacotherapy 2001;21:627-35.

46. Gallagher RM, Gallagher HC. Improving the working relationship between doctors and pharmacists: Is inter-professional education the answer? Adv Health Sci Educ Theory Pract 2012;17:247-57.

Affiliations: Faculties of Medicine and Pharmacy (Tannenbaum), Université de Montréal, Montréal, Que.; Epidemiology Coordinating and Research (EPICORE) Centre (Tsuyuki); Department of Medicine, Faculty of Medicine and Dentistry (Tsuyuki), University of Alberta, Edmonton, Alta.

Contributors: Both authors contributed substantially to the conception, research, design and drafting of the article, and gave final approval of the version submitted for publication. 